\title{
Nickase-dependent isothermal DNA amplification
}

\author{
Yan $\mathrm{He}^{1}$, Tao Jiang ${ }^{2 *}$ \\ ${ }^{1}$ Department of Biochemistry, Institute of Biotechnology, University of South China, Hengyang, China \\ ${ }^{2}$ Department of Genetics, Institute of Life Science \& Technology, Huazhong University of Science \& Technology, Wuhan, China \\ Email: $\underline{\text { Yanhe@126.com, }}$ tijiang20100@,hust.edu.cn
}

Received 16 January 2013; revised 5 March 2013; accepted 5 April 2013

Copyright (C) 2013 Yan He, Tao Jiang. This is an open access article distributed under the Creative Commons Attribution License, which permits unrestricted use, distribution, and reproduction in any medium, provided the original work is properly cited.

\begin{abstract}
We developed a nicking endonuclease dependent DNA amplification (NDA), using Nt.BstNBI to catalyze single-stranded nick on double-stranded DNA, and Bst DNA polymerase to make extension while sealing the nick and displacing the downstream strand. The displaced single-stranded DNA thereby serves as template for primers hybridization and extension, resulting in exponential synthesis of target DNA under isothermal condition. Over $10^{5}$ folds target DNA amplification can be achieved in 30 minutes, generating DNA product suitable for both diagnosis and DNA cloning. This NDA strategy does not re- quire thermal cycling or prerequisite nucleotides modification, making it suitable for application in the field and at the point-of-care.
\end{abstract}

Keywords: DNA Amplification; DNA Polymerase; Isothermal; Nickase; Strand Displacement

\section{INTRODUCTION}

DNA amplification is essential to most biological research involving nucleic acid manipulation. The polymerase chain reaction (PCR) has been a leading technique and been widely used in both research and clinical diagnostics [1,2]. But the requirement for sophisticated equipments has limited its application in unspecialized laboratories.

Several isothermal DNA amplification methods have been developed [3]. Strand displacement amplification (SDA) combines the ability of a regular restrictive endonuclease to nick a half-modified double-stranded DNA (dsDNA) and the action of an exonuclease-deficient DNA polymerase to extend the 3' end at the nick while displacing the downstream strand [4-6]. Loop-mediated

*Corresponding author. isothermal amplification (LAMP) employs a DNA polymerase and a set of four specific primers that recognize six distinct sequences on the target DNA, generating cauliflower-like stem-loop DNAs formed by annealing between inverted repeats [7]. Reported in 2004, helicasedependent amplification (HDA) uses a DNA helicase to separate dsDNA and generate single-stranded templates for primer hybridization and subsequent extension $[8,9]$. Most of the methods above need complex experimental procedures and their products are either too short to be used in further investigation or not compatible for cloning.

Nicking endonuclease (nickase) is a group of restrictive endonucleases that cleave only one strand of a dsDNA substrate $[10,11]$. It has been realized that they could be exploited in SDA [11-14] to replace the conventional restrictive enzymes, for which to make a nick on dsDNA, the cutting site must be half-modified. However, successful reports on using nickase in SDA are rare, probably because of high background amplification [15]. In this report we demonstrate that, by carefully choosing reaction conditions, successful amplification of target DNA can be achieved with little background. The products can be detected by gel electrophoresis and compatible with blunt-end cloning. This nickase-dependent amplification (NDA) provides a simple isothermal reaction scheme, with over a hundred thousand folds amplification in thirty minutes.

\section{MATERIAL AND METHODS}

\subsection{Material}

Lambda DNA and all enzymes were from New England Biolab. pUC18 DNA was from Fermentas. Human genomic DNA was extracted from whole blood sample collected in the $1^{\text {st }}$ affiliated hospital of University of South China, using a commercial kit from Sangong Shanghai, China. All oligonucleotides were from Sangong, Shanghai. 


\subsection{Methods}

\subsubsection{NDA Reactions for Amplifying Target Sequences}

When there were appropriate nickase recognition sites flanking the target sequence, a typical reaction protocol would be as follow: 1 - $100 \mathrm{ng}$ template DNA was mixed with $1 \mathrm{uM}$ of each primer, $0.4 \mathrm{mM}$ dNTP, $1 \mathrm{X}$ thermopol buffer $\left(20 \mathrm{mM}\right.$ Tris- $\mathrm{HCl}, 10 \mathrm{mM}\left(\mathrm{NH}_{4}\right)_{2} \mathrm{SO}_{4}, 10 \mathrm{mM}$ $\mathrm{KCl}, 2 \mathrm{mM} \mathrm{MgSO} 4,0.1 \%$ Triton X - 100, pH $8.8 @$ $\left.25^{\circ} \mathrm{C}\right), 10 \mu \mathrm{g}$ T4 gene 32 protein, 2 units Nickase, and 8 units Bst DNA polymerase. For nickase Nt.BstNBI and when target sequence was shorter than $200 \mathrm{bp}, 100 \mathrm{mM}$ $\mathrm{NaCl}$ would be included. The reaction mixture was brought to $25 \mathrm{ul}$ with double distilled water and incubated at $55^{\circ} \mathrm{C}$ to $65^{\circ} \mathrm{C}$ depending on the primers' $\mathrm{Tm}$ and the nickase chosen, for 30 to 60 minutes.

If there are no nickase recognition sites flanking the target sequence, a modification in procedure would be made. Template DNA would be mixed with a pair of primers, each with about 20 bases 5' overhanging for introduction of nicking sites, $0.4 \mathrm{mM}$ dNTP, $1 \mathrm{X}$ thermopol buffer. The mixture would be heated to $96^{\circ} \mathrm{C}$ and cooled to $55^{\circ} \mathrm{C}$ for primers annealing. 4 units of Bst DNA polymerase would be added to make extension at $65^{\circ} \mathrm{C}$ for 15 minutes. The mixture would be heat denatured again and incubated at $55^{\circ} \mathrm{C}$ to $65^{\circ} \mathrm{C}$ after $\mathrm{T} 4$ gene 32 protein, Nickase, and 8 units Bst DNA polymerase were added. The reactions were stopped by adding EDTA to $10 \mathrm{mM}$ and the products were analyzed on a $2 \%$ agarose gel containing ethidium bromide.

\subsubsection{Cloning of the Amplified Products}

Amplified products were ligated into pUC19/SmaI and transformed into E. coli JM109. Positive clones were sent to Sangong for sequencing.

\section{RESULTS AND DISCUSSION}

\subsection{NDA Design}

The reaction scheme of NDA is shown in Figure 1. In this system, target DNA is usually first digested by a double-cut restrictive enzymes (especially if there are no nickase recognition sites flanking the target sequence) (Figure 1, step 1). A pair of primers, with the sequence of 3' half complementary to the 3' ends of single-stranded template, the 5 ' half containing a nickase recognition site, will anneal to the target sequences after heating and cooling process (Figure 1, step 2). The mixture is then incubated with dNTP, nickase, and Bst DNA polymerase. Full length dsDNA will form by extension from 3' ends

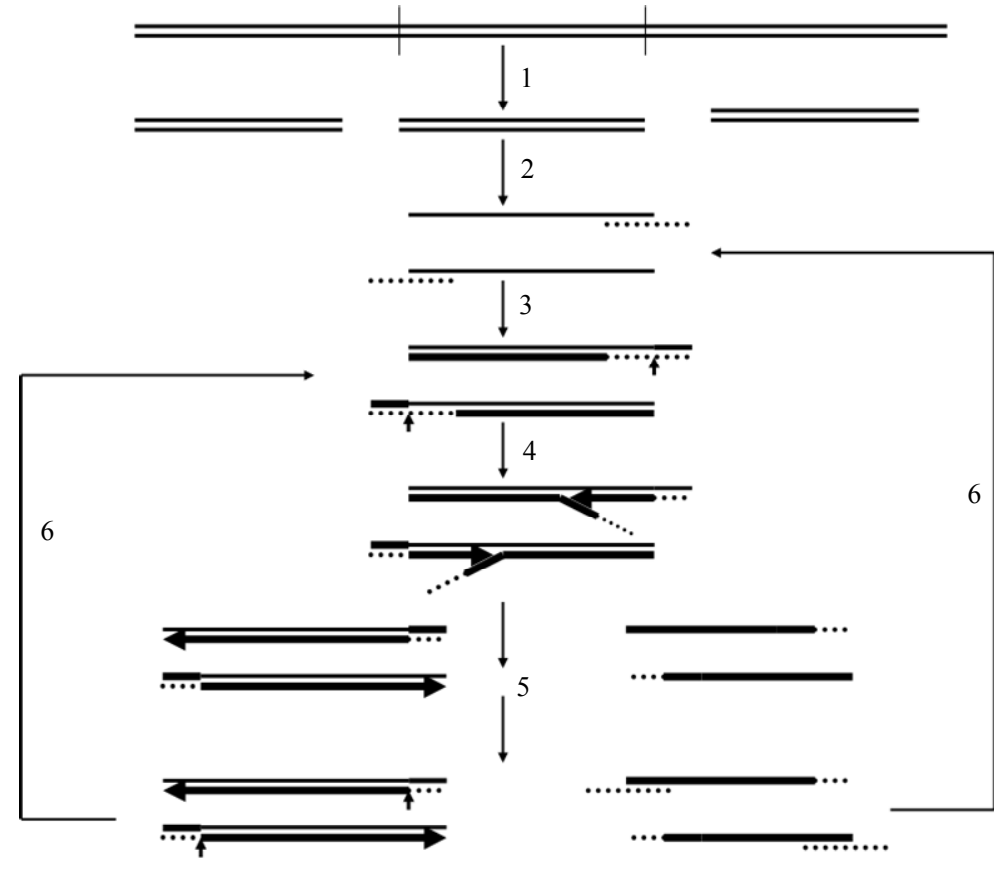

Figure 1. Schematic diagram of NDA. Newly synthesized DNA strands are shown as thick lines. 1) Target DNA (thin lines) is digested with restrictive endonuclease. 2) Primers (dotted lines) annealing to the templates after heating and cooling process. 3) Bst DNA polymerase makes extension to produce dsDNA, and nickase cleaves (upwards arrows) on one strand. 4) Bst DNA polymerase makes extension from 3'-OH of the nick while displacing the downstream strand. 5) Primers hybridize to the displaced single-stranded DNA. 6) Amplified products enter the new rounds of reaction. 
of both the hybridized primer and the template, generating a nicking site (Figure 1, step 3). The nickase will cleave on the strand extended from primer. And Bst DNA polymerase makes extension, sealing the nick and displacing the downstream strand (Figure 1, step 4).

The displaced single-stranded DNA will hybridize to the primers (Figure 1, step 5), triggering another round of extension-nicking-extension/displacing cycle (Figure 1, step 6, right). And the two newly synthesized dsDNA fragments will serve as substrates as well for nickase/ polymerase in the new round of reaction (Figure 1, step 6 , left), resulting in exponential amplification of the target sequence. When there were appropriate nickase recognition sites flanking the target sequence, the reaction can simply be initiated by incubating all components at appropriate temperature (not shown in Figure 1).

\subsection{Amplification of a $130 \mathrm{bp}$ Fragment from Lambda DNA}

To demonstrate the scheme, we used two primers to amplify a target sequence from lambda phage DNA (position 26,166 to 26,277 base pair). The primer I sequence is: 5'-GCAGCATTCTTGAGTCCAATATA AAAGTATTGTGTACC-3' and primer II is: 5'-TAATAGACTTATCGAGTCAAGAATCCCAAAGGGATATTTTCG-3', with about 20 bases at the 3' half matching the target sequences, and rest of the bases at 5 ' half for introducing nickase recognition sites and to stabilize the dsDNA complex after extension and nicking. Nickase Nt.BstNBI was used in the reaction, with recognition sequence as GAGTCNNNN $\downarrow$. Single band of about 130 bp (actually $131 \mathrm{bp}$ and $133 \mathrm{bp}$ fragments depending on which primer sequence they contain) with minimal background was observed on a $2 \%$ agarose gel after NDA reaction (Figure 2). Sequencing results of the amplified products confirmed that they matched the target DNA sequence. With template or Nt.BstNBI omitted, no significant amplification was observed, suggesting they were essential for the reaction (Figure 2(a), lanes 3 and 5). Inclusion of T4 gene 32 protein, a single-stranded DNA binding protein (SSB), could dramatically improve the efficiency Figure 2(a), lanes 1 and 2), with over a hundred thousand folds amplification achieved from $0.25 \mathrm{ng}$ lambda DNA, at $55^{\circ} \mathrm{C}$ in 30 minutes (Figure 2(b)).

\subsection{Amplification of up to 500 bp Fragment from Lambda and pUC18}

To test whether NSDA can be used to amplify DNA fragments longer than $130 \mathrm{bp}$, we designed pairs of primers to amplify target sequences with different lengths from pUC18 and lambda DNA. Specific target fragments of $509 \mathrm{bp}$ and $539 \mathrm{bp}$ can be successfully amplified from pUC18 and Lambda DNA, using Nt.BstNBI and another nickase Nt.BspQ1 (recognition sequence GCTCTTCN $\downarrow$ ), respectively. Target DNA products over $600 \mathrm{bp}$ could be seen on the gel, but with significant amount of non-specific bands or smeared DNA (data not shown).

\subsection{Discussion}

Using nickase instead of regular restrictive enzymes could greatly simplify the strategy of traditional strand displacement amplification. But successful reports about using nickase in amplifying target sequences are rare, if

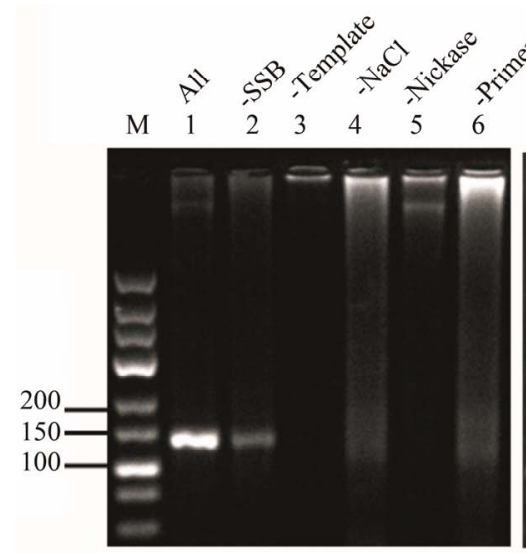

(a)

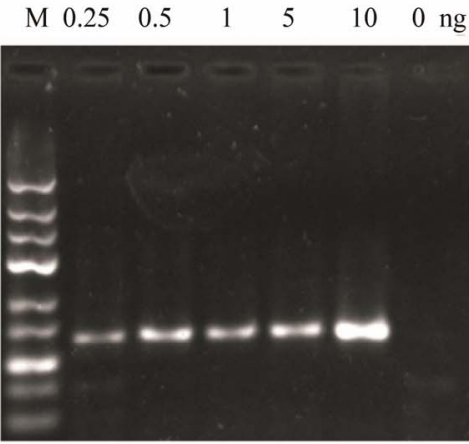

(b)

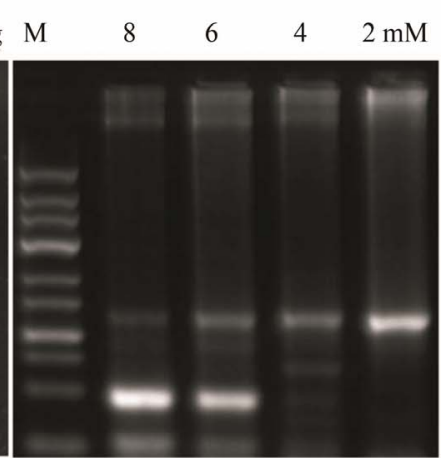

(c)

Figure 2. 2\% agarose gel electrophoresis of 131 and 133 - bp NDA products amplified from lambda DNA. All NDA reactions were performed at $55^{\circ} \mathrm{C}$ for 30 minutes. (a) NDA products in the presence of all components including 10 ng lambda DNA, Bst DNA polymerase, Nt.BstNBI, $100 \mathrm{mM} \mathrm{NaCl}$, primers I and II, T4 gene 32 protein (lane 1), and in the absence of T4 gene 32 protein (lane 2), lambda DNA (lane 3), NaCl (lane 4), Nt.BstNBI (lane 5) or primers (lane 6) are shown. (b) NDA products amplified from 0 - 10 ng lambda DNA with the amount shown above each lane. (c) NDA products amplified from 10 ng lambda DNA, with various concentrations of $\mathrm{Mg}^{2+}$, which are shown above each lane. M: GeneRuler ${ }^{\mathrm{TM}}$ Low Range DNA ladder (Fermentas). 
any. Based on our experiences, a possible reason might be the high background in the reaction involving nickase and Bst DNA polymerase. Zyrina et al. also reported that Nt.BstNBI stimulates highly efficient template-independent DNA synthesis by Bst DNA polymerase, with the mechanism unclear [15]. As we demonstrated here, that the background synthesis could be minimized by adjusting reaction conditions, namely by lowering $\left[\mathrm{Mg}^{2+}\right]$ to 2 $\mathrm{mM}$, increase the amount of Bst DNA polymerase, and use as little as possible the nickase. Combination of 8 units of Bst DNA polymerase and 2 units of nickase with $2 \mathrm{mM} \mathrm{Mg}{ }^{2+}$ presence was the optimal condition which efficiently generated specific products with very little background. $\left[\mathrm{Mg}^{2+}\right]$ higher than $2 \mathrm{mM}$ would generate smeared DNA or non-specific bands (Figure 2(c)). Reversal polymerase/nickase ratio had similar results (data not shown). It was known that $\mathrm{Mg}^{2+}$ is necessary for catalytic activity of restrictive enzymes, which can bind both cognate and non-cognate sequences with similar affinity, although showing various $\mathrm{Mg}^{2+}$ binding activity. We hypothesize that the background DNA synthesis may result from non-specific sequence recognition and digestion by nickase, which happens when nickase activity is too high and would serve as infinite "seeds" for amplification by polymerase. Using less nickase and lower amount of $\left[\mathrm{Mg}^{2+}\right]$ would minimize the occurrence of non-specific templates for polymerase, and hence minimize the background.

We demonstrated here that nicking endonuclease and Bst DNA polymerase can be successfully combined in amplifying specific target DNA with little background. Our ongoing efforts are applying NDA in DNA templates with high GC content, which can be difficult for PCR amplification.

\section{ACKNOWLEDGEMENTS}

This work was supported by Research Fund of University of South China, grant number \#504XJQ04002. We thank Dr. Weiwen Cai from Baylor College Medicine for instructive suggestion and comment in manuscript preparation.

\section{REFERENCES}

[1] Saiki, R.K., Gelfand, D.H., Stoffel, S., Scharf, S.J., Higuchi, R., Horn, G.T., Mullis, K.B. and Erlich, H.A. (1988) Primer-directed enzymatic amplification of DNA with a thermostable DNA polymerase. Science, 239, 487491. doi: $10.1126 /$ science. 2448875

[2] Taylor, G.R. and Robinson, P. (1998) The polymerase chain reaction, from functional genomics to high-school practical classes. Current Opinion Biotechnology, 9, 35-

\section{2. doi:10.1016/S0958-1669(98)80081-5}

[3] Gill, P. and Ghaemi, A. (2008) Nucleic acid isothermal amplification technologies-A review. Nucleosides $\mathrm{Nu}$ cleotides Nucleic Acids, 27, 224-243. doi:10.1080/15257770701845204

[4] Walker, G.T., Little, M.C., Nadeau, J.G. and Shank, D.D. (1992) Isothermal in vitro amplification of DNA by a restriction enzyme/DNA polymerase system. Proceedings of National Academic Science of the USA, 89, 392-396. doi:10.1073/pnas.89.1.392

[5] Walker, G.T., Fraiser, M.S., Schram, J.L., Little, M.C., Nadeau, J.G. and Malinowski, D.P. (1992) Strand displacement amplification-An isothermal, in vitro DNA amplification technique. Nucleic Acids Research, 20, 16911696. doi:10.1093/nar/20.7.1691

[6] Walker, G.T. (1993) Empirical aspects of strand displacement amplification. PCR Methods Application, 3, 1-6. doi:10.1101/gr.3.1.1

[7] Notomi, T., Okayama, H., Masubuchi, H., Yonekawa, T., Watanabe, K., Amino, N. and Hase, T. (2000) Loop-mediated isothermal amplification of DNA. Nucleic Acids Research, 28, e63. doi:10.1093/nar/28.12.e63

[8] Vincent, M., Xu, Y. and Kong, H. (2004) Helicase-dependent isothermal DNA amplification. EMBO Rep, 5, 795800. doi:10.1038/sj.embor.7400200

[9] An, L., Tang, W., Ranalli, T.A., Kim, H.J., Wytiaz, J. and Kong, H. (2005) Characterization of a thermostable UvrD helicase and its participation in helicase-dependent amplification. Journal of Biological Chemistry, 280, 2895228958. doi:10.1074/jbc.M503096200

[10] Kong, H., Higgins, L., Dalton, M., Kucera, R. and Schildkraut, I. (2001) Cloning and producing the N.BstNBI nicking endonuclease. US Patent No. 6191267.

[11] Chan, S.H., Zhu, Z., Van Etten, J.L. and Xu, S.Y. (2004) Cloning of CviPII nicking and modification system from chlorella virus NYs-1 and application of Nt.CviPII in random DNA amplification. Nucleic Acids Research, 32, 6187-6199. doi:10.1093/nar/gkh958

[12] Van Ness, J., Galas, D. and Van Ness, L. (2006) Nucleic acid amplification using nicking agents. US Patent No. 7112423.

[13] Kucera, R. (2007) Genome amplification. International Patent No. WO/2007/056173.

[14] Yao, Z. and Lidgard, G. (2008) Method for rapid, singlestep strand displacement amplification of nucleic acids. International Patent No. WO/2008/066979.

[15] Zyrina, N.V., Zheleznaya, L.A., Dvoretsky, E.V., Vasiliev, V.D., Chernov, A. and Matvienko, N.I. (2007) N.BspD6I DNA nickase strongly stimulates template-independent synthesis of non-palindromic repetitive DNA by Bst DNA polymerase. Biological Chemistry, 388, 367-372. doi:10.1515/BC.2007.043 